Dr. P. Lacombe (France) contributed jointly with Prof. Guinier a paper on the use of a curved crystal as a monochromator and as a means for focusing X-rays, which in conjunction with a powder camera gives very sharp contrast photographs. Small quantities of impurities can be detected and complicated structures can be analysed.

Dr. V. Petržílka (Charles University, Prague) described an X-ray method for orientation of cut quartz crystal plates by means of an adapted Seeman spectrograph. A small indentation in its knife edge shows on the $K$ and $L$ lines of the spectrum on the film as black spots. The position of these spots is a function of the orientation of the crystals, and from one photograph it is possible to determine both principal angles and to control and test cut or finished quartz plates.

Dr. P. Skulari (Ceskoslovenská Zbrojovka, Prague) discussed the close collaboration of the X-ray worker with the engineer. By such collaboration, technolog. ical processes can be corrected and guided, density and porosity determined and casting controlled. $\mathrm{He}$ also described how X-ray analysis elucidated the working properties of zinc and zinc alloys which possess a hexagonal structure. This structure is sensitive to working processes. Anisotropy and twinning are also contributing causes to the working properties. The best mechanical properties are achieved by slow cold-working or by repair of the damaged structure by annealing followed by quenching. Dr. I. Smoler gave his experiences on the X-ray analysis of crystalline compounds, chiefly inorganic, by the powder method. Analysis consisted of comparison of the diffraction pattern with a standard, or calculation of the lattice. The method was applied to titanium white (rutile-anatase), to refractory materials, to cements for dentists, and many other substances. Dr. B. G. Simek (Coal Research Institute, Prague) spoke about the radiography of coals. In black coal inorganic materials can be detected, whereas brown coal gives continuous blackening. The structure of coke can be investigated by filling its cavities with barium sulphate. Brickettes were investigated by adding lead soap in the binder. He then spoke about the X-ray analysis of coals. Reactivities of graphite and various cokes were measured and compared with $\mathrm{X}$-ray results, giving the size of the crystallites. The powder method was used and the photographs measured with a recording microphotometer. Colloid dispersions of carbon in pitch and their properties were also studied.

Major J. Sterner (U.S. Army) spoke about some recent developments of apparatus for X-ray purposes, such as vibrating microphotometers, registering the first derivative of blackening, and $\mathrm{X}$-ray planigraphy.

Prof. P. Urbain (Institut Ernest Denis, Prague) referred to the use of powder methods in the investigation of hydrated aluminium, magnesium and iron silicates in clays and soils. The specimens should be purified by electrophoresis with high values of electric fields to eliminate quartz, oxides and carbonates. The diffraction pattern is thus simplified. The metacolloids can then be classified according to their long spacings into four groups : Kaolinite-halloysite (6.959.65 A.) of aluminium type; nontronite (10-11 A.) containing iron and also aluminium; sepielite (11$13 \cdot 5$ A.) containing magnesium and also aluminium; montmorillonite (14-15 A.) containing aluminium and magnesium.

Dr. V. Vand (Lever Brothers, Port Sunlight) contributed a description of the progress in the construc- tion of X-ray tubes and apparatus in Great Britain and the United States. Powder and focusing cameras and moving film techniques were also described.

M. Vinopal (Meta, Prague) gave a general outline of the evolution and history of the Czechoslovak X-ray industry.

Dr. J. Wanka (Society for Chemical and Mining Manufacture) spoke about the testing by radiography of a complicated chemical plant. Welds and boilers were tested, and as accessibility was very difficult, various methods were used. Dr. K. Waitzmann (Research and Testing Institute for Building Materials, Prague) described the testing of materials by means of $\gamma$-rays from radium, radon and mesothor. ium. The time of exposure is shortened by reinforcing foils. In steel and concrete, cavities of different sizes can be detected. By means of a comparison wedge, the thickness of the cavities can be determined. Mrs. Wooster (Cavendish Laboratory, Cambridge) spoke about the use of X-rays in conjunction with the Weissenberg camera in the study of orientation of crystals, and in the testing of industrial diamonds. Dr. L. Zachoval (Ako, Ceský Brod) sent a contribution about the methods of sensitometry of $\mathrm{X}$-ray emulsions and appealed for a standardization of the procedure. A Scheiner astroboscopic disk and a source of controlled X-ray output is recommended; for lower accuracy, a wedge is sufficient.

Dr. Kunzl (Charles University, Prague) summarized the results of the meetings.

V. VAND.

\section{VENEREAL DISEASE IN WEST AFRICA}

\author{
By MAJOR R. R. WILLCOX
}

Late Command Venereologist, West African Command

\section{Incidence}

$T$ HE incidence of venereal disease in West African natives is very high indeed, and is rapidly on the increase. The exact number of cases in the Colonies is difficult to assess, but in British coloured troops in Nigeria, for example, the gonorrhcea rate alone was more than 60 per cent per annum; while the venereal disease rate in Gold Coast troops was 50 per cent per annum; in Sierra Leone 28 per cent; and in the Gambia as low as 12 per cent.

Gonorrhcea is by far the most common venereal disease, and the women in the larger towns are nearly all infected. The virtual total absence of facilities to treat the women on any scale at all makes the problem a most acute one. Soft sore and lymphogranuloma inguinale are both very prevalent, while syphilis, though taking fourth place, is also very rife.

\section{Treatment Facilities}

The British Army, on the whole, is organised to give adequate treatment to its personnel and to render them free from infection. The main difficulty is that the men are constantly being reinfected by the women. Some hospitals have venereal diseases clinics attached to them; while at others, such as Bathurst in the Gambia and Lagos in Nigeria, actual clinics have recently been opened. The relative numbers of female attendances at these centres are not many. Most civilian hospitals have a venereal diseases ward for males but there are usually no darkground condensers available for diagnostic purposes, 
and most of the cases of penile sore receive neoarsphenamine until the sores are healed, and little or no after-treatment is given. The females are, as a rule, admitted to the gynæcological wards, usually only when complications have developed.

Staff shortages are acute and financially the building and staffing of clinics is tapensive; therefore the civilian medical authorities, while conscious of the position, feel that the measures required to tackle it are at present beyond their powers, and that other diseases, like sleөping sickness, leprosy and-as yet to be organised on any scale-tuberculosis, should take pride of place.

\section{Gonorrhœa}

Gonorrhœe runs a similar course as in Britain, but in the West African repeated attacks are much more frequent though the incidence of complications seemed lower. Between 80 and 90 per cent responded to adequate sulphonamide dosage; but the resistant cases were very resistant indeed, though they reacted well to penicillin.

The main difficulty of sulphonamide therapy was the fact that unless the tablets were crushed and given to the men by the medical officer personally, they would often not be taken but sold in the nearest town or village for one shilling a tablet. Partly for this reason, the previous standard Army treatment at units for gonorrhœa had consisted of intramuscular injections of crushed sulphapyridine tablets, $1 \mathrm{gm}$. daily for four days, which in my experience was unsatisfactory. The difficulty was overcome by giving an adequate dose of sulphathiazole $(6 \mathrm{gm}$.) in one draught daily for three days, and there then remained only twelve pints of water to be administered daily by the orderlies. Complications with sulphathiazole so administered were negligible, and all failures were sent to hospital, where latterly they received penicillin.

The improvement generally was dramatic. Success. rates claimed at units varied on the average between 80-90 per cent (one unit treated 295 cases in three months with only five failures), and hospital admissions decreased enormously. Thus there is obviously no truth in the widely disseminated rumour that the West African gonococcus is sulphonamide-resistant.

\section{Syphilis}

Opportunities of examining children were small, but though the numbers of stillbirths and abortions were high, one did not see many congenital syphilitics. Perhaps they did not survive. Primary syphilis was common and became more so as it was insisted that all sores received adequate dark-ground tests. The dark-ground tests were the only sure way of diagnosing syphilis, as in areas like Accra in the Gold Coast endemic yaws rendered serological tests unreliable for the purpose. In some weeks more than half the bloods examined showed positive reactions.

It is sometimes supposed that the existence of a positive blood test due to a previous yaws infection is a protection against syphilis. Findlay and Willcox (1945), however, successfully infected with primary syphilis a man whom one of them had treated for yaws some years previously and who had a positive Kahn reaction at the time of the experiment.

Secondary syphilis, too, was common and pustular syphilides were frequently met. Many rashes were called secondary yaws, and it was often difficult to decide which of the two disorders to diagnose; but as one saw so many primary sores and knew too that so many received inadequate treatment, one inclined toward syphilis in doubtful cases. Late syphilis was also common in the Army.

Civilian treatment for syphilis, usually after depending on Kahn test diagnosis only, was weekly neoarsphenamine until the sore had healed, and it was considered impossible or impracticable to continue after this. Army treatment was much the same at first, but has since been organised on more orthodox lines with three courses of arsenic and bismuth. The defaulter rate is, however, very high.

Penicillin will be a great boon when it becomes available for civilian use, for the Army cases responded well to the drug. As a generalization, it is not so serious for the patient to default after the penicillin course as the total treatment required for that case has usually been given. If civilian hospitals are supplied with dark-ground condensers to diagnose syphilis and penicillin with which to treat it, a very substantial move will have been made towards combating this disorder.

\section{Soft Sore}

This disease is extremely prevalent-more so than syphilis. If the basic rules are applied, namely, three negative dark-ground tests before local treatment is applied and sulphonamides administered orally, the majority heal quickly and little trouble is experienced. Associated buboes are common.

Serological tests are unreliable for excluding syphilis owing to the possible previous infection with yaws.

\section{Lymphogranuloma Inguinale}

This disease, though very common, was no real menace to troops, at any rate, though civilian medical men on the Coast said it was different in presulphonamide days. One had very few chronic cases and I cannot recall boarding anyone out of the Army for this condition. I aspirated and even incised buboes and they healed without difficulty. One medical officer-a locum tenens-made long incisions on his fluctuent cases, including one European, but these too healed within two or three weeks. One can only imagine that the disease earned its bad name in the days before the sulphonamides, when surgeons made sweeping excisions of the glands. Rectal strictures occurred in females and were seen in civilian hospitals in Sierra Leone and Nigeria.

Treatment was general rather than local. Hot fomentations and the like applied to buboes appeared to be ineffective and expensive as to time and materials and personally were not used. Ulcerated groins were powdered with sulphanilamide powder and a dry dressing applied. Sulphonamides by mouth in orthodox doses were very effective indeed, and if further treatment was required, antimony in the form of 'Anthiamaline' was given. If these measures failed, a further course of sulphonamides with intravenous T.A.B. was employed. The average stay in hospital for all cases was nine days, while about 6 per cent relapsed.

Intravenous T.A.B. was well tolerated by the African though about 50 per cent showed some signs of liver damage as judged by urine and blood laboratory findings 24-48 hours after an injection.

Penicillin was tried and in small doses of 100,000 200,000 units was $60-70$ per cent successful but was 
not so effective as the sulphonamides. Better results were obtained in larger doses of one million units.

\section{Other Venereal Diseases}

Balanitis and penile warts were seen, but taking into account the religious ban on circumeision in many West African tribes, were less common than might be expected. Non-specific urethritis was comparatively rare, most suspected cases being attributable to gonorrhœa. I was able to find trichomonas vaginalis in several of the women I examined, while pediculosis pubis and scabies with its usual genital lesions were also common.

Of the rarer conditions, gandou was seldom seen in the Army, and as for granuloma venereum, I was only able to find one text-book case in a woman in northern Nigeria. I had none in my own department at Accra and saw none in my visits to other military hospitals.

\section{Self-inflicted Lesions}

Dishonesty as regards to property is rife in West Africa, and this dishonesty extends on a large scale to the production of self-inflicted lesions in order to avoid fatigues, postpone imprisonment or discharge from hospital, or to try to get out of the Army. This took on many forms.

Self-inflicted urethral discharge was very common; toothpaste, prophylactic tubes, whitewash, ointments and the latex of certain plants like Euphorbia being the commonest agents employed, while actual gonoccal pus was used by prisoners in the guard room. The absence of pus in the smear of the chemically produced cases indicated the diagnosis, and intravenous T.A.B. often exerted a salutary cure.

Penile sores were usually manufactured with battery acid or plant juices, and again Euphorbia played its part. If carelessly done, as was usually the case, the scattered auxiliary lesions made nakedeye diagnosis easy. If carefully done, they could be very difficult to distinguish from soft sore.

Conjunctivitis was another frequently self-inflicted lesion, and if occurring in someone already with gonorrhoea was often hard to detect, as were swollen knees induced by trauma.

\section{Other Tropical Conditions}

Several other tropical conditions infringed on the venereal field and did much to make the work interesting. Many patients with cystitis or hæmaturia, for example, had bilharzia; while many, too, suffered from filariasis, usually loa loa and often symptomless. Occasionally the adult worm was seen migrating across the conjunctiva, and once the microfilariæ of loa loa were seen while examining a blood-stained urine. Obviously, the patients with the giant scrota were not admitted to the Army, but one saw a number with the lesser grades of genital œdema. Microfilariæ, usually of loa loa, were demonstrated in the blood in the majority of these, and the attack, which usually was not the first, subsided in about a week. In one of these cases the lymphatic-borne microfilariæ of the Onchercerca volvulus were found in a skin scraping. The presence of the latter in the eye leads to a considerable amount of blindness in the northern territories of the Gold Coast.

Another parasite was the larva of the tumbu fly. This fly lays eggs on the ground, which are picked up by the clothes should they be allowed to dry

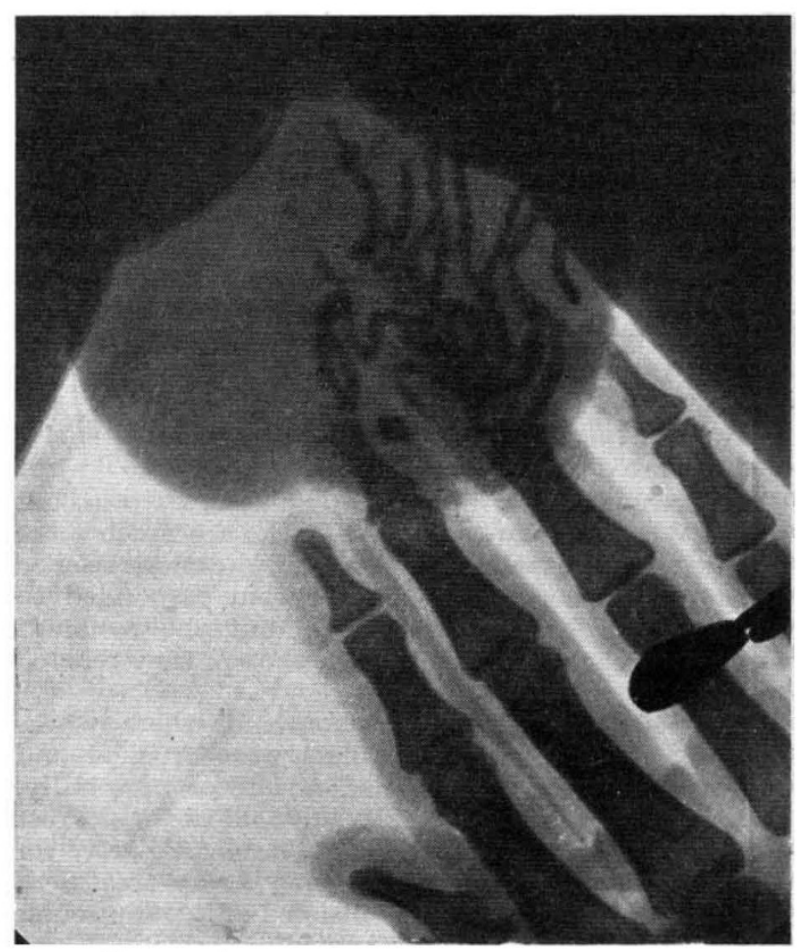

X-RAY SHOWING OALCIFIED GUINEA WORM IN SCROTUM

there after washing, and larvæ from these eggs burrow into the skin, where a chrysalis develops, which with scratching leads to an infected painful sore. I saw one of these in the glans penis of a European who had complained some ten days before of having been bitten by an ant. Occasionally they may be expressed in squeezing a scrotal sore for dark-ground examination.

Guinea worms, too, were sometimes seen invading the genital area, and their larvæ were once identified microscopically in a discharging scrotal sore. Calcified worms were occasionally felt alongside the epididymis and could be confirmed by X-ray.

Hydroceles are very common in the African, though considering the amount of gonorrhca it is not surprising. Also common is a pyogenic infection of the scrotum, which heals rapidly after incision and evacuation of much pus. Whether this is due in the first place to trauma, tumbu fly, guinea worm, self-infliction or to some other cause is not known.

\section{Prophylaxis}

Perhaps the most alarming factor of all is the general failure of all known methods of prophylaxis in the West African.

Prophylactic centres are a failure. In one unit where they were tried energetically, 40 per cent of the men had gonorrhoea before they used the centre and were visiting it only to protect themselves from disciplinary action before reporting sick. In another unit every man leaving the camp was given compulsory prophylactic treatment on his return whether he admitted exposure to infection or not. However, owing to men leaving the camp without permission, women being brought in, or to lack of diligence on behalf of the African orderly, there was no reduction in venereal disease there over a three months trial. In yet another unit where the prophylactic room was used enthusiastically (there being between twenty 
and thirty users a night and a full-time African orderly on duty) there were in spite of this more than three hundred cases of venereal disease in three months.

Thus with an untreated heavily infected female population, and with a practically complete failure in male prophylaxis, we are up against a gigantic and grave problem. In addition, the mobilization of an army in West Africa has caused a large-scale and widespread redistribution of population with increased dissemination of these diseases. Therefore, the already vast problem is likely to increase further and further both in numbers and extent.

So far, the Colonial medical authorities find themselves unable to deal with the matter and, indeed, in many areas express themselves defeated before they have started. Postponement of facing up to this medical scourge is only making it more difficult each month that it is left, and each month the bill that will one day have to be paid mounts higher. As the Army pulls out of West Africa it will become solely the concern of the Colonial Medical Service; but by this time it will be beyond the powers of the Colonial medical officers already stationed there and of the fow clinics at present erected.

It will have to be tackled as an epidemic, with maps and mobile diagnostic and treatment centres, with teams of full-time doctors and orderlies, and with litres of penicillin, treating village by village, town by town, until slowly and surely each Colony is cleared to the extent that local hospitals could hope to deal with the residue. That, I fear, will be the only way by which venereal disease will be controlled in these Colonies; it has already gone too far for other measures to hope to succeed; but such measures are, one suspects, too Utopian at the present time.

For the present, the best line is to concentrate on making one fixed class of African reasonably cleanthat is, the educated African. Teach them in the schools, at the universities, and by all means possible, how to dislike and avoid venereal disease and provide the means by which they can get treated if they become infected. Then slowly, as the clerks, the telegraphists and the printers emerge from their technical training, they will become venereal disease conscious.

Unfortunately, one realizes only too well the immense difficulties, especially at the present time. All the same, one must wonder whether sufficient attention is paid to the question of venereal disease in West Africa.

\section{FISHERIES OF JAMAICA}

GROM April 1943 until October 1944, Dr. E. F. 1 Thompson (now on the staff of the Bingham Oceanographic Laboratory) carried out an exhaustive survey of the fisheries of Jamaica with the view of assessing their needs and making recommendations for their betterment.

In an excellent and comprehensive report*, Dr. Thompson presents convincing evidence in support of his general conclusion that so far as Jamaica is concerned "there are too many men trying to catch too few fish"; that the potential of the available fishing areas is already fully exploited, and that,

* Development and Welfare in the West Indies. Bulletin No. 18: The Fisheries of Jamaica. Report by Dr. Frnest F. Thompson. Pp. 104. (Barbados: Advocate Co., Ltd., 1945.) 30 cents. therefore, any extensive modernization and indus. trialization of the industry would lead to unemployment, increased eatching and distribution costs, and no increase in production. The recommendation is therefore made that country fishermen should be encouraged to keep or renew their contacts with agriculture, so that eventually many of them may fish chiefly as an additional and subsidiary source of income and of variation of diet for themselves and their immediate neighbours.

In recommending this policy the author points out that he is well aware that it is the reverse of that generally made by advocates of modern industrialized methods. Apparently he fears disapproval of this recommendation.

He need not do so. Only where fishing grounds are inadequately exploited can modern methods be profitably introduced. To increase fishing intensity on grounds already overfished would be reprehensible and suicidal. No better advice could be tendered than that "mixed farming become a little more 'mixed' to include some farming by coastal agriculturists", and that a proportion of fishermen be encouraged to join such communities. In fact, a counterpart of the Scottish crofter-fisherman is envisaged-a type that industrialization in Britain has now all but extinguished, and Scotland is undoubtedly the worse for it.

Progress along these lines is bound to be slow and it is pointed out that, in the meantime, the greatest need of Jamaican fishermen is more in the nature of welfare than development-perhaps the most important pronouncement in the whole of the report, and applicable not only to Jamaica but also to all other backward regions where fisheries development and similar schemes are either contemplated or already in operation.

In so far as Jamaica is concerned, the aims of such welfare work are stated to be: (1) provision of an organisation through which fishermen and their problems can be handled in a natural and orderly manner ; $(2)$ the accumulation of savings to stabilize the fishermen's living and help them to assume responsibility for their own future; (3) to organise co-operative marketing; (4) to act as a liaison between fishermen and organisations working for the social and economic betterment of the people; (5) to renew and increase fishermen's contacts with agriculture and assist about four-fifths of them to drift back to agriculture from whence they came.

Dr. Thompson is under no delusion that in Jamaica -as in all other places where such development and welfare schemes are needed-all these efforts will fail in their purpose unless right and adequate responses are stimulated in those they are designed to benefit. Whether progress be achieved by the introduction of modern methods and equipment or by other means, this hard fact must always be faced-that competitive effort must be put forth with competitive zeal, enterprise and dependability. Where these are, as he found, so sadly lacking they must be evoked and developed or the outlays of both money and effort on grandiose schemes will do no more than bring about a brief and spurious prosperity to be followed by failure, disillusionment, and distress even more acute than before. All those concerned with development and welfare projects in all parts of the world would do well to ponder carefully over the final sentence in Dr. Thompson's report, "While optimism is always welcome, careful thought should be taken lest false hopes be raised and unnecessary suffering caused". 